\title{
Examined the Ability of Some Different Equations of State in Predicting Thermodynamic Properties of Nitrogen Gas at Different Conditions Rang of Pressure and Temperature
}

\author{
Ali Lateef Tarish \\ Asst. Lecture, Thermal Mechanics, Eng. Dept., Southern Technical University, Basra, Iraq
}

*Corresponding Author: Ali Lateef Tarish, Asst. Lecture, Thermal Mechanics, Eng. Dept., Southern Technical University, Basra, Iraq

\begin{abstract}
In the present work, examined the ability of some different equations of state (EOS) in predicting thermodynamic properties (density, thermal conductivity, specific heat at constant pressure and constant volume) of nitrogen gas at different conditions rang of pressure and temperature. Also describe how those properties are influenced by relationship to the critical point or by crossing the liquid gas curve in the $P-T$ plane. Therefore the landscape of thermodynamic properties of the nitrogen fluid is unclear at real cycle, here a comprehensive analytical study of the five appropriate equations of state namely, ideal gas equation (IE), Van Deer Waals (VDW), Beattie-Bridgeman (BB), Benedict-Webb-Rubin (BWR) and Martin-Hou (MH) and its thermodynamic properties is presented to determine the suitable equation. The behavior of nitrogen fluid properties in five equations was calculate by Engineering Equation Solver (EES) programming. The results are compared with experimental data and the recommended values of standard thermodynamic tables for nitrogen. The results, which gives very favorable, namely $3 \%$ maximum error in predicting thermodynamic properties. The results at high pressure show that the BWR is in better agreement with the data experimental than the VDW and BB. However, only at very low pressures the VDW, IE gives a better result.The thermal conductivity value result for the pressure range (1-10MPa) is not suitable used with the MH because the deviation was finding $7 \%$.
\end{abstract}

Keywords: thermodynamic properties, equations of state, Nitrogen.

\section{INTRODUCTION}

Test data are necessary because properties at low temperatures are often significantly different from those at ambient temperature. The application of cryogenic engineering has become extensive. For example, the food industry uses large amounts of liquid nitrogen to freeze the more expensive foods like shrimp and to maintain frozen food during transport [1]. Nitrogen produce cooling when expanded across a valve. Accordingly, this fluid can be used directly as the refrigerant in a throttling process without the necessity of a precooling step or expansion through a work-extracting device. Liquid nitrogen is of considerable importance to the cryogenic engineer because it is a safe refrigerant, it rather inactive chemically and is neither explosive nor toxic, liquid nitrogen is commonly used in hydrogen and helium liquefaction cycles as a precoolant. Nitrogen is the major constituent of air ( $78.09 \%$ by volume or $75.45 \%$ by weight). The atmosphere of Mars, by comparison, is $2.6 \%$ nitrogen. The estimated amount of this element in our atmosphere is more than 4000 billion tons. From this in exhaustible source, it can be obtained by liquefaction and fractional distillation. Liquid nitrogen is a clear, colorless fluid that resembles water in appearance. At 1 bar pressure, liquid nitrogen boils at $77.3 \mathrm{~K}$ and freezes at $63.2 \mathrm{~K}$. Saturated liquid nitrogen at the normal boiling point has a density of $808.9 \mathrm{~kg} / \mathrm{m}^{3}$. Table 1 show properties of nitrogen gas [2]. Property tables provide very accurate information about the properties, but they are bulky and vulnerable to typographical errors. A more practical and desirable approach would be to have some simple relations among the properties that are sufficiently general and accurate. Any equation that relates the pressure, temperature, and specific volume of a substance is called an equation of state. Property relations that involve other properties of a substance at equilibrium states are also referred to as equations of state. There are several equations of state, some simple and others very complex [3].The thermodynamic properties calculated are found to be satisfactory in the region from atmospheric up to critical pressure, including 
the saturated and superheated zones, and in the region above the critical pressure. It is therefore concluded that thermodynamic properties in both the subcritical and supercritical regions can be accurately predicted by the BWR equation of state with the previously determined eight coefficients. The predicted densities in the range from atmospheric pressure to near critical pressure accurately agree with the experimental data. However, the deviation increases slightly with pressure [4]. Wei and Richard [5] progress in developing equations of state for the calculation of fluid-phase equilibrium. It is now quite common to use molecular simulation data to test the theoretical basis of equations of state. Hossein Eslami [6] performed an analysis based on liquid density of halogenated hydrocarbons is calculating an analytical EOS, the EOS used with much less input information than the full potential, because the temperature-dependent parameters of the equation of state that depend only on the repulsion ( $a$ and $b$ ); are insensitive to the detailed shape of the potential and can be scaled with two fixed constants. Nasri far and Bolland [7] predictive accuracy of the EOS is comparable to the predictive accuracy of the RKS of EOS. The supercritical behavior of methane by using the VDW mixing rules with zero binary interaction parameters, the proposed EOS predicts the compressibility factors and speeds of sound data of natural gas mixtures with best accuracy among the other EOS. Hossein Eslami and et.al [8] performed an the equation of state had calculated using our previous corresponding states correlation based on the normal boiling point temperature and the liquid density at the normal boiling point for temperature dependent parameters. Eirini Karakatsani [9] evaluated four molecular-based EOS developed aiming at the prediction and correlation of thermodynamic properties of polar fluids and mixtures. Mahmood Farzaneh and et.al [10] presented a numerical method and a computer program to calculate the thermal properties of natural gas mixture such as enthalpy and internal energy in addition of the compressibility factor using EOS.

In this work, it is intended to examined the ability of five EOS, ideal gas equation (IE),Van Deer Waals (VDW), Beattie-Bridgeman (BB), Benedict-Webb-Rubin (BWR) and Martin-Hou Equation $(\mathrm{MH})$ in predicting thermodynamic properties (density, thermal conductivity, specific heat at constant pressure and constant volume) of nitrogen gas at wide range of pressure and temperature. Also describe how those properties behavior are influenced by proximity to the critical point or by crossing the liquid-gas coexistence curve in the P-T plane.

\section{APPROPRIATE EQUATION OF STATE}

The examined the accuracy of some different equations of state in low and high range of the pressure and temperature for predicting thermodynamic properties such as the following equation:

\subsection{Ideal Gas Equation}

The simplest and best-known equation of state for substances in the gas phase is the ideal-gas equation of state. This equation predicts the P-v-T behavior of a gas quite accurately within some properly selected region, where the constant of proportionality. The ideal-gas equation of state is very simple, but its range of applicability is limited [11].

$P v=R T$

In this paper can be finding the limitation of ideal gas equation at different range for temperature and pressure for nitrogen gas.

\subsection{Van Deer Waals Equation}

The VDW is the simplest and most widely known example of an interacting system of particles that exhibits a phase transition, in this case a first-order transition between liquid and gas (vapor) phases. The accuracy of the VDW equation of state is often inadequate, but it can be improved by using values of $\mathbf{a}$ and $\mathbf{b}$ that are based on the actual behavior of the gas over a wider range instead of a single point. The VDW equation equal [12]

$\mathrm{PV}=\mathrm{RT}-\left(\frac{\mathrm{a}}{\mathrm{V}}\right)+\mathrm{bP}$

The determination of the two constants as the following:

$a=\frac{67 R^{2} T_{c}}{64 T_{c}} \quad b=\frac{R T_{c}}{8 P_{c}}$ 
$P_{\text {crit }}=\frac{3 R T_{\text {crit }}}{2 v_{c}}-\frac{9 R T_{\text {crit }}}{8 v_{c}}$

Where the critical point is a point in $\mathrm{P}-\mathrm{V}-\mathrm{T}$ space defined by the highest possible temperature and the highest possible pressure for which distinct liquid and gas phases can be observed.

\subsection{Beattie-Bridgeman Equation of State (BB)}

The Beattie-Bridgeman equation is an equation of state based on five experimentally determined constants. It is expressed as [13]:

$P=\left(R_{u} \frac{T}{v^{2}}\right)\left(1-\frac{C}{v T^{3}}\right)(v+B)-\left(\frac{A}{v^{2}}\right)$

$A=A_{o}\left(1-\frac{a}{v}\right)$ and $B=B_{o}\left(1-\frac{b}{v}\right)$

The constants appearing in the above equation are given in Table 2 for various substances.

\subsection{Benedict-Webb-Rubin Equation of State (BWR)}

One of the early analytical equations for fluid states for the vapor phase was proposed by Beattie and Bridgeman by raising the number of constants to eight. The values of the constants appearing BWR equation are given in Table 2. It is expressed as [14]:

$P=\left(R_{u} \frac{T}{v}\right)+\frac{\left(B_{o} R_{u} T-A_{o}-\frac{C_{o}}{T^{2}}\right)}{v^{2}}+\frac{b R_{u} T-a}{v^{3}}+a \frac{\alpha}{v^{6}}+\frac{c}{T^{2} v^{3}}\left(1+\frac{\gamma}{v^{2}}\right)\left(e^{-\frac{\gamma}{v^{2}}}\right)$

\subsection{Martin-Hou Equation of State (MH)}

Real gas represented by the Martin-Hou Equation (MH) of State as the following:[15]

$$
\begin{gathered}
P=\frac{R T}{v-b}+\frac{A_{2}+B_{2} T+C_{2} e^{-\beta T / T c}}{(v-b)^{2}}+\frac{A_{3}+B_{3} T+C_{3} e^{-\beta T / T c}}{(v-b)^{3}}+\frac{A_{4}+B_{4} T+C_{4} e^{-\beta T / T c}}{(v-b)^{4}} \\
+\frac{A_{5}+B_{5} T+C_{5} e^{-\beta T / T c}}{(v-b)^{5}}+\frac{A_{6}+B_{6} T+C_{6} e^{-\beta T / T c}}{e^{a v}\left(1+C e^{a v}\right)}
\end{gathered}
$$

\subsection{Constant Pressure and Volume Heat Capacities of Nitrogen}

The constant pressure heat capacity calculated from

$C_{p}=C_{p}^{*}(T)+T \int_{\infty}^{v}\left(\partial^{2} p / \partial T^{2}\right)_{v} d v-\frac{T\left[(\partial p / \partial T)_{v}\right]^{2}}{\left(\frac{\partial p}{\partial v}\right)_{T}}-R$

The constant volume heat capacity calculated from

$C_{v}=C_{v}^{*}(T)+T \int_{\infty}^{v}\left(\partial^{2} p / \partial T^{2}\right)_{v} d v$

Table1. Properties of Nitrogen $(R=296.8 \mathrm{~J} / \mathrm{kg} . \mathrm{k}) R=R u / M, \quad M=28.02$

\begin{tabular}{|l|l|}
\hline Property & Nitrogen \\
\hline Normal boiling point $(\mathrm{K})$ & 77.347 \\
\hline Density $\left(\mathrm{kg} / \mathrm{m}^{3}\right)$ & 808.9 \\
\hline Heat of vaporization $(\mathrm{kJ} / \mathrm{kg})$ & 198.3 \\
\hline Specific heat $(\mathrm{kJ} / \mathrm{kg} . \mathrm{k})$ & 2.04 \\
\hline Viscosity $(\mathrm{kg} / \mathrm{m} . \mathrm{s}) \times 10^{6}$ & 157.9 \\
\hline Thermal conuctivity $(\mathrm{mW} / \mathrm{m} . \mathrm{K})$ & 139.6 \\
\hline Dielectric constant & 1.434 \\
\hline Critical temperature $(\mathrm{K})$ & 126.20 \\
\hline Critical pressure $(\mathrm{MPa})$ & 3.399 \\
\hline Temperature at triple point $(\mathrm{K})$ & 63.148 \\
\hline Pressure at triple point $\left(\mathrm{MPa} \times 10^{3}\right)$ & 12.53 \\
\hline
\end{tabular}


Examined the Ability of Some Different Equations of State in Predicting Thermodynamic Properties of Nitrogen Gas at Different Conditions Rang of Pressure and Temperature

Table2. Constants that appear in the Beattie-Bridgeman and the Benedict-Webb-Rubin equations of state [15]

\begin{tabular}{|l|l|l|l|l|l|}
\hline \multicolumn{6}{|l|}{ Beattie-Bridgeman EOS } \\
\hline Gas & Ao & a & Bo & b & c \\
\hline Nitrogen & 136.2315 & 0.02617 & 0.05046 & -0.00691 & $4.2 \times 10^{4}$ \\
\hline
\end{tabular}

\begin{tabular}{|c|c|c|c|c|c|c|c|c|}
\hline \multicolumn{9}{|c|}{ Benedict-Webb-Rubin EOS } \\
\hline Gas & $\mathrm{a}$ & Ao & $\mathrm{b}$ & Bo & $\mathrm{c}$ & $\mathrm{Co}$ & $\alpha$ & $y$ \\
\hline Nitrogen & 2.54 & 106.73 & 0.002328 & 0.04074 & $7.379 \times 10^{4}$ & $8.164 \times 10^{5}$ & $1.272 \times 10^{-4}$ & 0.0053 \\
\hline
\end{tabular}

\section{Computerize Programming OF EES}

The nitrogen gas properties are updated using the most current property data from EES 2016. This program can be using for real and ideal gas, the temperatures range from 63.151 to $1000 \mathrm{~K}$ and pressures to $2200 \mathrm{MPa}$. However, particular attention must be paid to the reference states if the gas is to be used in calculations involving chemical reactions. The enthalpy of formation and third law entropy values at $298 \mathrm{~K}$ and 1 bar must be supplied. For example, the first line in the sample file contains User Fluid. The enthalpy for this substance would then be obtained as follows. h=Enthalpy (User Fluid, $\mathrm{T}=\mathrm{T} 1, \mathrm{P}=\mathrm{P} 1$ ). The fluid name will appear in alphabetical order with other fluid names in the Function Information dialog window. A comment follows on the same line (after one or more spaces) to identify the number. The forms of all of the correlations except the pressure-volumetemperature relation are indicated in the XFLUID.MHE file.

\section{RESULTS AND DISCUSSION}

The results that will be reviewed in this section are for the thermodynamic properties of nitrogen. All mathematical equations were established for the processes through are modeled using EES-software. The simulated results are compared with the experimental data and with the similar results that obtained by other researcher.

Figure 1 shows the density of nitrogen at variation of the pressure, which the pressure is change from (1-10MPa) at temperature (100-700k), the test show all equations of state (IE, VDW, BB, BWR, and $\mathrm{MH})$ get same value for density at the temperature range (300-700k), because the range for pressure is below critical pressure (3.39MPa).Figure 2,3 shows the converge the results between $\mathrm{BB}$ and BWR equations until the pressure reach to $\mathrm{P}=10 \mathrm{MPa}$, while the equations $\mathrm{BB}, \mathrm{BWR}$, IE and $\mathrm{MH}$ give same results until pressure reach to $10 \mathrm{MPa}$ expect VDW give grate value compare with previous results, for example at $\mathrm{P}=10 \mathrm{MPa}$ and $\mathrm{T}=27^{\circ} \mathrm{C}$, the density of all equation is $\left(112 \mathrm{~kg} / \mathrm{m}^{3}\right)$ while the VDW equation equal to $\left(116.7 \mathrm{~kg} / \mathrm{m}^{3}\right)$.The results for the density, thermal conductivity, specific heat at constant pressure and constant volume of nitrogen gas was compare with reference $[16,17]$ as shows in Tables $3,4,5$ and 6. Figure 4 shown as a gas is increasing pressure $(2.6-3.5 \mathrm{MPa})$ and temperature $\left(-196^{\circ} \mathrm{C}\right)$, the density is increasing linearly so if the temperature is constant, increasing the pressure results in a corresponding increase in density and vice-versa. Note that this only holds under the assumption of constant temperature, because the average spacing between molecules becomes less and the fraction of the macroscopic gas volume occupied by the microscopic molecules increasing. Figure 5 illustrate at low pressure $(100-200 \mathrm{kPa})$ and temperature $\left(-196^{\circ} \mathrm{C}\right)$, the density line rise from $\left(5-850 \mathrm{~kg} / \mathrm{m}^{3}\right)$ and fluctuate unit the pressure reach $400 \mathrm{kPa}$ the density remain constant because of the real gas effects of nitrogen [18], and increasing of the pressure on an object decreases the volume of the object and thus increases its density. Figure 6 shown the temperature verses with density at pressure (0.1-20MPa). Increasing the temperature of a liquid nitrogen until reach to $-190^{\circ} \mathrm{C}$ caused small decreases its density by increasing its volume. While the grater change in the density happened at the temperature fall to $190^{\circ} \mathrm{C}$ and the liquid nitrogen converted to gas, this change because the critical temperature of nitrogen. 
Examined the Ability of Some Different Equations of State in Predicting Thermodynamic Properties of Nitrogen Gas at Different Conditions Rang of Pressure and Temperature



Fig1. Experimental data and estimated IE EOS of nitrogen

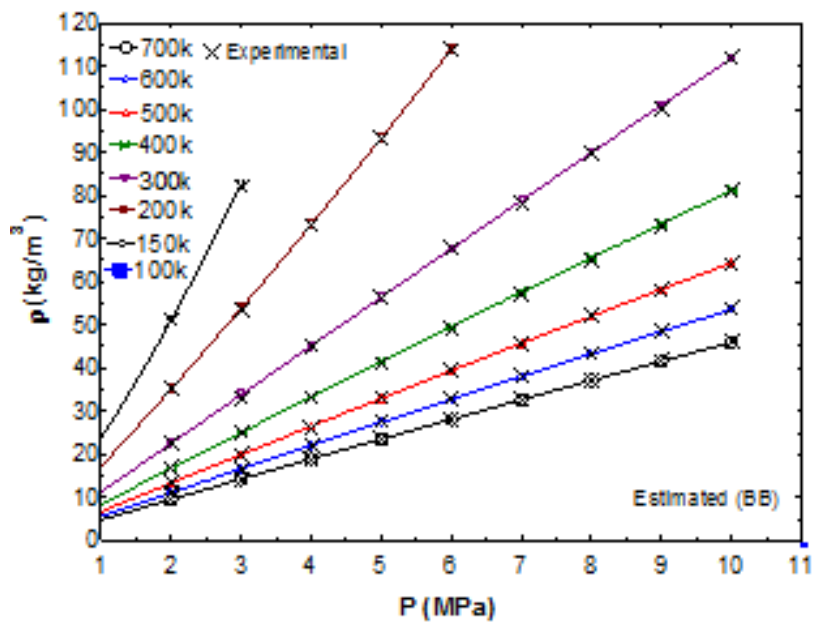

Fig2. Experimentaldata and estimatedBB EOS of nitrogen

Figure7 presented the relation between density and pressure for all EOS with EXP, the temperature range is changed from (100-700k) the VDW equation not gives good results at compare with IE, BB and BWR results; at compare EXP with BB find the maxim error is $2.5 \%$, and compare EXP with BWR find the maxim error equal $1 \%$. The error average at compare results with experimental as the following: $\mathrm{EXP} \& \mathrm{BWR}=1 \%, \mathrm{EXP}$ and $\mathrm{BB}=2.1 \%$. From above results can be finding the $\mathrm{BB}$ equation not give the accuracy results, while the BWR give best results at compare with EXP.

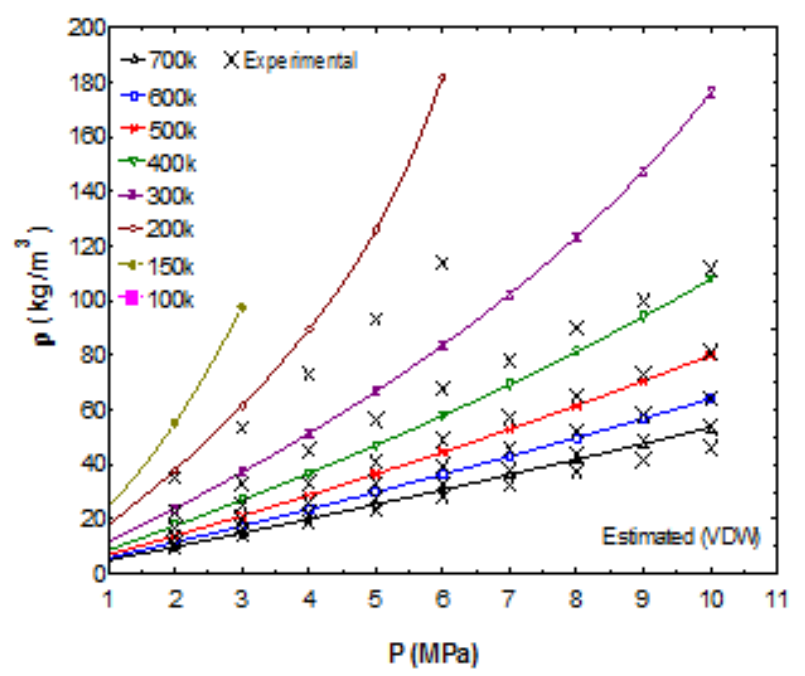

Fig3. Experimental data and estimated VDW EOS of nitrogen 


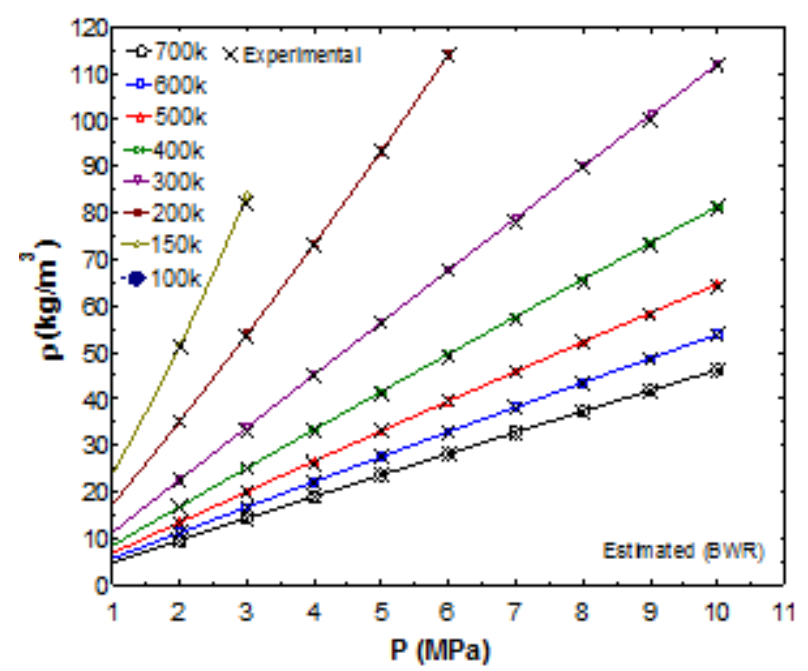

Fig4. Experimental data and estimated BWR EOS of nitrogen



Fig5. Experimental data and estimated MH EOS of nitrogen

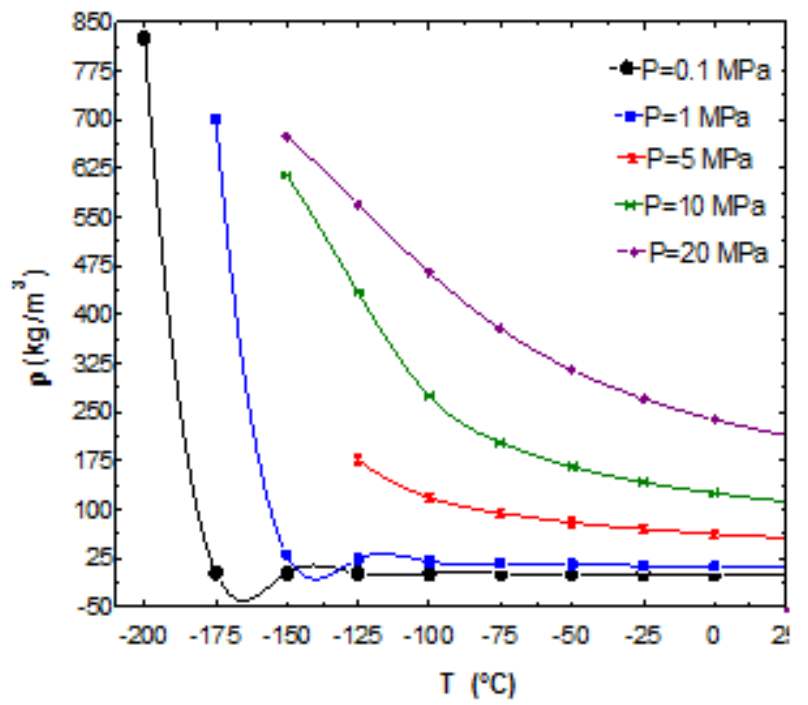

Fig6. Deviation plot for predicting the density of nitrogen with temperature

Figure 8 shown variation of pressure and $\mathrm{Cp}$, the constant pressure specific heat $\mathrm{Cp}$ is the slope of the enthalpy-versus-temperature curve for a substance undergoing a process conducted at constant 
Examined the Ability of Some Different Equations of State in Predicting Thermodynamic Properties of Nitrogen Gas at Different Conditions Rang of Pressure and Temperature

pressure. The Cp increasing from dip $(1.04 \mathrm{~kJ} / \mathrm{kg} . \mathrm{k})$ until reach to peak and leveled off at $(1.35$ $\mathrm{kJ} / \mathrm{kg} . \mathrm{k}$ ), because the transient in pressure to critical pressure (3.3MPa). The variation of temperature with $\mathrm{Cp}$ for a wide range of nitrogen temperature $\left(-200^{\circ} \mathrm{C}\right.$ to $\left.50^{\circ} \mathrm{C}\right)$. As noted from the figure, $\mathrm{Cp}$ decreases at increases with temperature, $\mathrm{Cp}$ values are nearly constant with temperature in the range $\left(50^{\circ} \mathrm{C}\right.$ to $\left.-175^{\circ} \mathrm{C}\right)$, while considerably increase with temperature decreased. For both real and ideal gases, the specific heat $\mathrm{Cp}$ is function of temperature. The specific heats of real gases also possess a pressure dependence. For gases, the temperature dependence of $\mathrm{Cp}$ is a consequence of the internal energy storage modes become increasingly active as temperature increases. The data are drawn versus $\mathrm{Cv}$ with pressure as a parameter, this behavior curve same as $\mathrm{Cp}$, because $\mathrm{Cv}$ is the slope of the internal energy versus-temperature curve for a substance undergoing a process conducted at constant volume. In Figure 9 the pressure values are plotted against $\mathrm{k}$ at temperature $\left(-190\right.$ to $\left.25^{\circ} \mathrm{C}\right)$, it may be noted that increasing in pressure caused increasing of the $\mathrm{k}$ from $(0.025-0.085)$.

Table3. Compare the IE, VDW, BB, BWR, and EXP for density value

\begin{tabular}{|l|l|l|l|l|l|l|l|l|}
\hline \multicolumn{9}{|c|}{ Density $\left(\mathrm{kg} / \mathrm{m}^{3}\right)$} \\
\hline $\mathrm{P}(\mathrm{MPa})$ & $\mathrm{T}\left({ }^{\circ} \mathrm{C}\right)$ & BB & BWR & VDW & MH & IE & EXP [16,17] & \\
\hline 0.1 & -195.8 & 4.551 & 4.5 & 4.49 & 4.557 & 4.364 & 4.6121 & \\
\hline 0.1 & 20 & 1.15 & 1.149 & 1.15 & 1.15 & 1.15 & 1.1648 & \\
\hline
\end{tabular}

Table4. Compare estimated with EXP for Cp value

\begin{tabular}{|c|c|c|c|}
\hline \multicolumn{4}{|c|}{ Cp } \\
\hline P(MPa) & T ( ${ }^{\mathbf{0}} \mathbf{C}$ & Estimated & EXP [16,17] \\
\hline $\mathbf{0 . 1}$ & $\mathbf{- 1 9 5 . 8}$ & 1.3 & 1.124 \\
\hline $\mathbf{0 . 1}$ & $\mathbf{2 0}$ & 1.042 & 1.041 \\
\hline
\end{tabular}

Table5. Compare estimated with EXP for Cv value

\begin{tabular}{|c|c|c|c|}
\hline \multicolumn{3}{|c|}{ Cv } \\
\hline P(MPa) & T $\left.\mathbf{(}^{\mathbf{0}} \mathbf{C}\right)$ & Estimated & EXP [16,17] \\
\hline $\mathbf{0 . 1}$ & $\mathbf{- 1 9 5 . 8}$ & 0.93 & 0.7714 \\
\hline $\mathbf{0 . 1}$ & $\mathbf{2 0}$ & 0.774 & 0.743 \\
\hline
\end{tabular}

Table6. Compare estimated with EXP for $K$ value

\begin{tabular}{|c|c|c|c|}
\hline \multicolumn{3}{|c|}{ k (w/m.k) } \\
\hline P(MPa) & T ( $\left.{ }^{\mathbf{0}} \mathbf{C}\right)$ & Estimated & EXP [16,17] \\
\hline $\mathbf{0 . 1}$ & $\mathbf{- 1 9 5 . 8}$ & 0.00765 & 0.00719 \\
\hline $\mathbf{0 . 1}$ & $\mathbf{2 0}$ & 0.0254 & 0.2547 \\
\hline
\end{tabular}

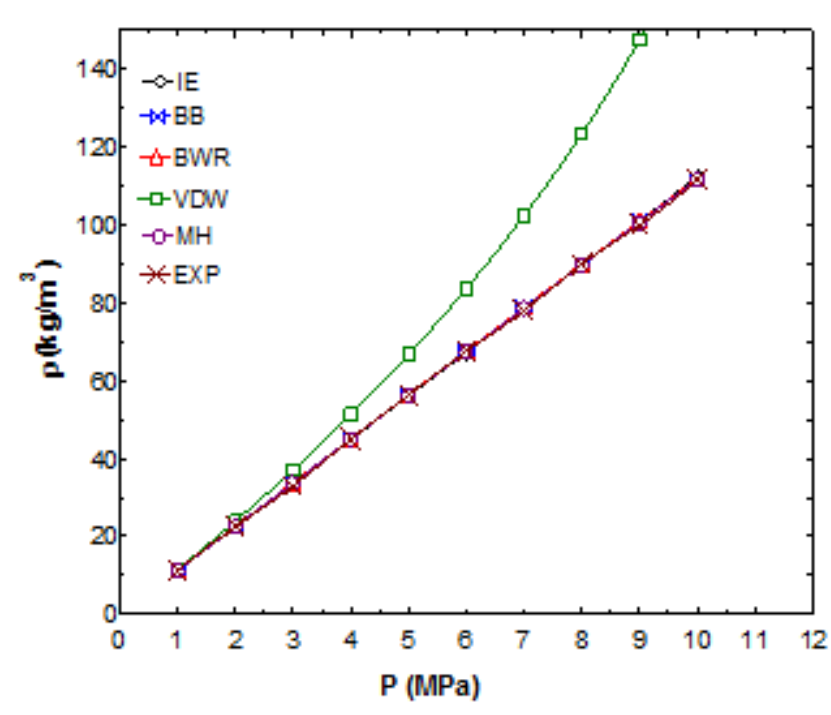

Fig7. Estimated five EOS and EXP. Data 


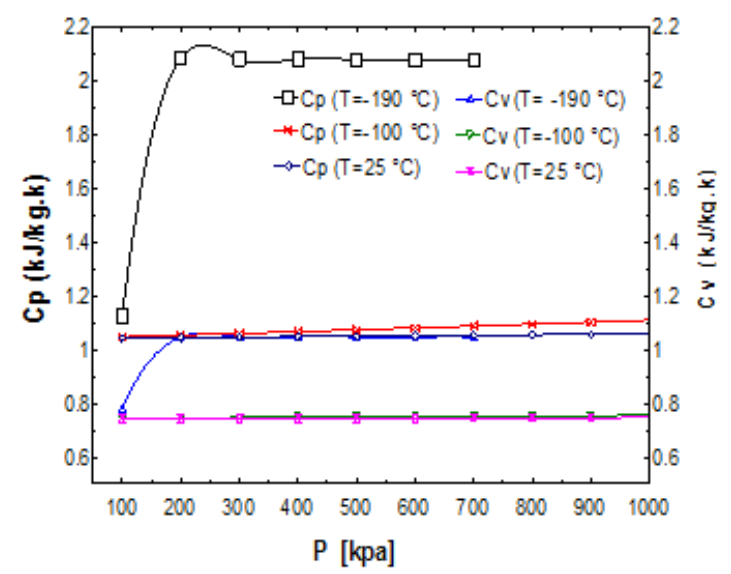

Fig8. Variation of $C p$ and $C v$ with pressure at temperature range (25 to -190C)

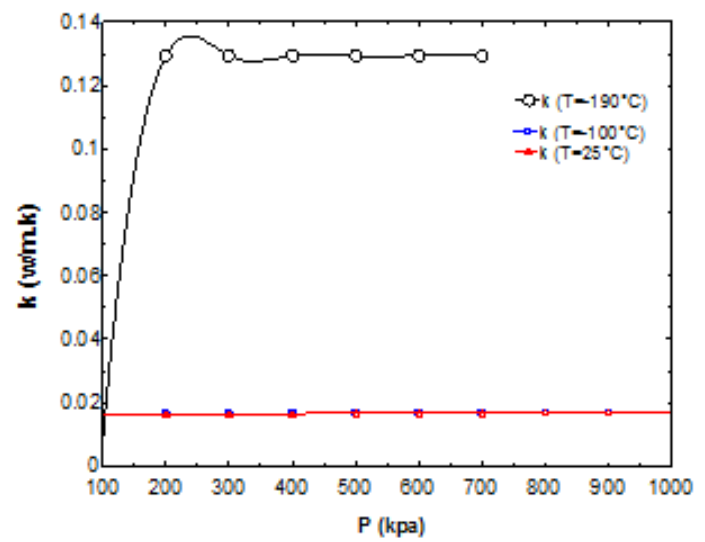

Fig9. Change the pressure with thermal conductivity

\section{Conclusions}

Calculations performed in this study made it clear that for predicting the properties of nitrogen for the whole range (saturated and supercritical conditions) as the following:

1. The MH EOS is accurate and robust. Therefore is recommended for most applications connected with nitrogen. For predicting nitrogen properties at temperatures less than 200k, almost all five EOSs can be used with comparable accuracy.

2. However, the best comparative for predicting different nitrogen properties are summarized in Table 3,4,5,6.

3. In the low density range, five equations of state, give more accurate results, therefore we recommend them for the calculation thermodynamic properties.

4. The results show that the MH is in better agreement with the experimental data than the VDW, especially at high densities.

\section{LIST OF SYMBOLS}

\begin{tabular}{|c|l|c|c|c|}
\hline Symbol & \multicolumn{1}{|c|}{ Description } & Units & Abbreviation & \multicolumn{1}{c|}{ Description } \\
\hline $\mathrm{a}$ & Constant of VDW & $\mathrm{m}^{3} / \mathrm{Kg}$ & BWR & Benedict-Webb-Rubin \\
\hline $\mathrm{b}$ & Constant of VDW & $\mathrm{m}^{6} \cdot \mathrm{kPa} / \mathrm{kg}^{2}$ & $\mathrm{BB}$ & Beattie-Bridgeman \\
\hline $\mathrm{C}_{\mathrm{p}}$ & Specific heat at constant pressure & $\mathrm{kJ} / \mathrm{kg} \cdot \mathrm{k}$ & $\mathrm{IE}$ & Ideal gas equation \\
\hline $\mathrm{C}_{\mathrm{v}}$ & Specific heat at constant volume & $\mathrm{kJ} / \mathrm{kg} \cdot \mathrm{k}$ & $\mathrm{VDW}$ & Van deer weels \\
\hline $\mathrm{K}$ & Thermal conductivity & $\mathrm{w} / \mathrm{m} \cdot{ }^{\circ} \mathrm{C}$ & $\mathrm{MH}$ & Martin-Hou \\
\hline $\mathrm{P}$ & Pressure & $\mathrm{kPa}$ & $\mathrm{EES}$ & Engineering equation solver \\
\hline $\mathrm{P}_{\mathrm{cr}}$ & Critical pressure & $\mathrm{kPa}$ & $\mathrm{RKW}$ & Redlich Kwong Soave \\
\hline $\mathrm{R}$ & Gas constant & $\mathrm{kJ} / \mathrm{kg} \cdot \mathrm{k}$ & $\mathrm{EXP}$ & Experimental \\
\hline $\mathrm{T}$ & Temperature & ${ }^{\circ} \mathrm{C}$ & & \\
\hline $\mathrm{V}$ & Specific volume & $\mathrm{m}^{3} / \mathrm{kg}$ & & \\
\hline $\mathrm{V}$ & Volume & $\mathrm{m}^{3}$ & & \\
\hline$\rho$ & Density & $\mathrm{kg} / \mathrm{m}^{3}$ & & \\
\hline
\end{tabular}




\section{REFERENCES}

[1] ASHRAE Handbook "Refrigeration" American Society of Heating, Refrigeration and Air conditioning Engineers, Chapter 39, USA, 1998.

[2] Thomas M. Flynn “Cryogenic Engineering”, USA, 2005.

[3] Yunus and Boles "Thermodynamics: An Engineering Approach", fifth edition, McGraw-Hill's, 2000.

[4] Asami and Ebisu "Thermodynamic properties of nitrogen calculated from the BWR equation of state" Japan, 1988.

[5] Wei and Richard "Equations of State for the Calculation of Fluid-Phase Equilibrium" AIChE Journal January 2000 Vol. 46, No. 1 Australia.

[6] Hossein Eslami, "An analytical equation of state for refrigerants" International Journal of Refrigeration 27 (2004) 649-655.

[7] Nasrifar and Bolland "Prediction of thermodynamic properties of natural gas mixtures using 10 equations of state including a new cubic two-constant equation of state" Journal of Petroleum Science and Engineering 51 (2006) 253-266.

[8] Hossein Eslami and et.al "An analytical equation of state for refrigerant mixtures" International Journal of Refrigeration 29 (2006) 150-154.

[9] Eirini Karakatsani "Development and Evaluation of a New Equation of State for Polar Fluids: Pure Components and Mixtures" PhD thesis, the National Technical University of Athens, Greece in May 2007.

[10] Mahmood Farzaneh and et.al "Computing Thermal Properties of Natural Gas by Utilizing AGA8 Equation of State" International Journal of Chemical Engineering and Applications, Vol. 1, No. 1, June 2010.

[11] Claus and Sonntagn "Fundamentals of Thermodynamic" seven edition, John Wiley \& Sons, Inc., 2009. Printed in the United States of America.

[12] Sanford Klein and Gregory Nellis "Thermodynamic Concepts" Cambridge University Press, 2012.

[13] Desmond Winterbone "Advanced Thermodynamics for Engineers" John Wiley \& Sons, he., New York, 1997.

[14] Richard and Lemmon "Thermodynamic Properties of Cryogenic Fluids" USA, 1997.

[15] Kalyan and Puri. "Advanced thermodynamics engineering" 2002. CRC Press LLC, United States of America.

[16] ASHRAE Handbook "Fundamental" American Society of Heating, Refrigeration and Air conditioning Engineers, Chapter 20, USA, 2005.

[17] Vargaftik and et.al "Handbook of physical properties of liquids and gases (pure substances and mixtures)", 3rd edition, New York, 1996.

[18] Poling and et. al "The Properties of Gases and Liquid" Fifth Edition, McGRAW-HILL, 2001.

Citation: A. Lateef Tarish, "Examined the Ability of Some Different Equations of State in Predicting Thermodynamic Properties of Nitrogen Gas at Different Conditions Rang of Pressure and Temperature", International Journal of Advanced Research in Chemical Science (IJARCS), vol. 4, no. 5, pp. 21-29, 2017. http://dx.doi.org/10.20431/2349-0403.0405003

Copyright: (c) 2017 Authors. This is an open-access article distributed under the terms of the Creative Commons Attribution License, which permits unrestricted use, distribution, and reproduction in any medium, provided the original author and source are credited. 